M.C. JONES
R.M. GILGENBACH
${ }^{1}$,
B. QI
Y.Y. LAU
G.L. DOLL

\section{Ablation plasma ion implantation using a dc power supply}

\author{
${ }^{1}$ Intense Energy Beam Interaction Laboratory, Nuclear Engineering and Radiological Sciences Department, \\ University of Michigan, Ann Arbor, Michigan 48109-2104, USA \\ 2 Advanced Materials Technology, Timken Research, The Timken Corporation, Canton, \\ Ohio 44706-0939, USA
}

Received: 25 September 2003/Accepted: 17 December 2003 Published online: 26 July $2004 \cdot$ C C Springer-Verlag 2004

ABSTRACT Experiments are reported in which ablation plasma ion implantation (APII) has been demonstrated using a dc power supply. The ability to use a dc power supply for APII has been accomplished by using a perpendicular orientation between the target and the substrate. This perpendicular orientation significantly reduces the arcing between the target and the substrate, in contrast to previous experiments using a parallel targetsubstrate orientation. With this new technique a $\mathrm{KrF}$ laser may be fired during the dc high voltage, accelerating full-energy ions. Initial experiments using dc APII have shown that Ti is deposited and implanted onto the Si substrate, with the highest concentration of Ti located beneath the surface of the film. The deposition/implantation of Ti ions onto Si was verified by X-ray photoelectron spectroscopy.

PACS 52.38.Mf

\section{$1 \quad$ Introduction}

Plasma immersed ion implantation (PIII) has become an established materials processing technique since the original experiments by Conrad et al. [1,2]. PIII has found applications to tool hardening $[1,3]$, semiconductor processing [4-6], corrosion resistance [7, 8], and, most recently, biocompatible materials for medical implants $[9,10]$. In conventional PIII, a pulsed negative high-voltage bias is applied to the workpiece, which is immersed in a dc plasma, typically from a gaseous precursor. Previous experiments by $\mathrm{Chu}$ et al. have attempted to use a dc voltage for PIII [11-13]. In the past several years ablation plasma ion implantation (APII) has been demonstrated to accelerate, implant, and deposit ions ablated from solid targets of metals [14-17]. Until recently, a pulsed voltage was applied to the workpiece, synchronized and delayed with respect to the laser ablation pulse to avoid arcing. However, the utilization of a pulsed, high-voltage power supply or switch tube is relatively expensive for industrial applications compared to a dc power supply.

In this article we present experimental data demonstrating ablation plasma ion implantation utilizing a dc power supply

Fax:+1-734/763-4540, E-mail: rongilg@umich.edu using a new substrate-target configuration, which has been shown to alleviate the problem of arcing for dc, as previously achieved in pulsed mode $[14,17]$. This new dc APII process could greatly reduce both the cost and the complexity of plasma ion implantation systems for future industrial or medical applications.

\section{$2 \quad$ Experimental configuration}

The experimental configuration is depicted in Fig. 1. Figure $1 \mathrm{a}$ shows the basic experiment. A KrF laser (Lambda Physik COMPex 205) generates up to $600 \mathrm{~mJ}$ in a $20-\mathrm{ns}$ pulse at a wavelength of $248 \mathrm{~nm}$. The laser beam is focused onto the target to create a plasma plume, the ions of which are accelerated towards the biased substrate. The negative dc voltage is transmitted into the vacuum chamber through a $100-\mathrm{kV}$-rated insulator. The pulse-repetition rate of the laser pulses is between 1 and $10 \mathrm{~Hz}$. The experiment is pumped down with a turbomolecular pump to an ultimate pressure of $10^{-7}$ Torr. A high-voltage probe and current transformer are used to measure the electrical signals. A digital delay generator controls the timing of the laser, while a digital oscilloscope measures the electrical signals.

Figure 1b schematically illustrates the perpendicular orientation of the target to the substrate. This configuration has been demonstrated to eject electrons from the gap to alleviate arcing between the substrate and the target. This perpendicular target-substrate orientation also results in pure ion implantation with negligible deposition of neutral atoms and particulates on the substrate surface $[14,17]$.

\section{$3 \quad$ Results and discussion}

Typical electrical signals from dc APII are shown in Fig. 2. For comparison, these signals show that in the previous parallel target-substrate orientation the voltage (Fig. 2a) shorts out from plasma arcing as the laser is fired. In the new perpendicular target-substrate orientation, the power-supply voltage (Fig. 2b) is loaded down from $-10 \mathrm{kV}$ to $-5 \mathrm{kV}$ once the laser is fired. However, arcing does not occur as the voltage recovers to its full value of $-10 \mathrm{kV}$ within about $40 \mu \mathrm{s}$. A higher-current dc supply or larger capacitors on the output of the voltage source would reduce this voltage droop. 

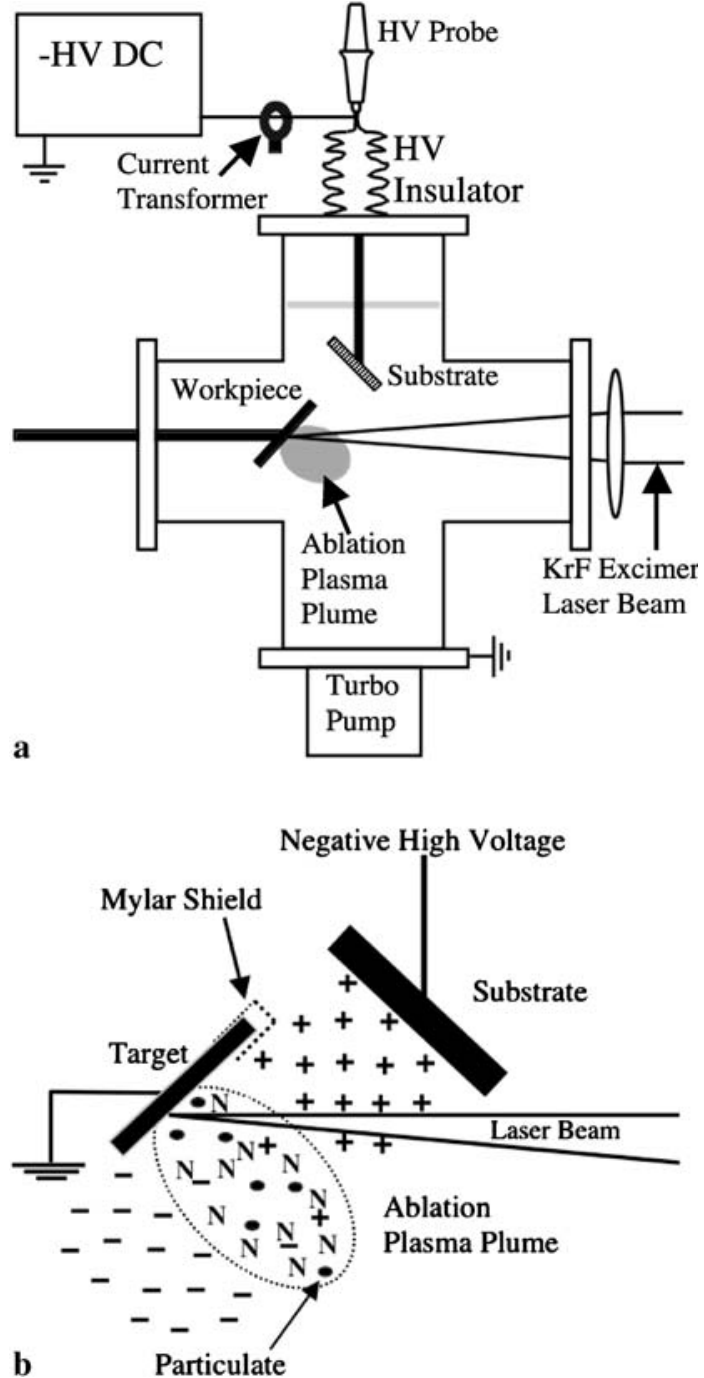

FIGURE 1 a dc APII experimental configurations. b Schematic of target surface perpendicular to substrate position

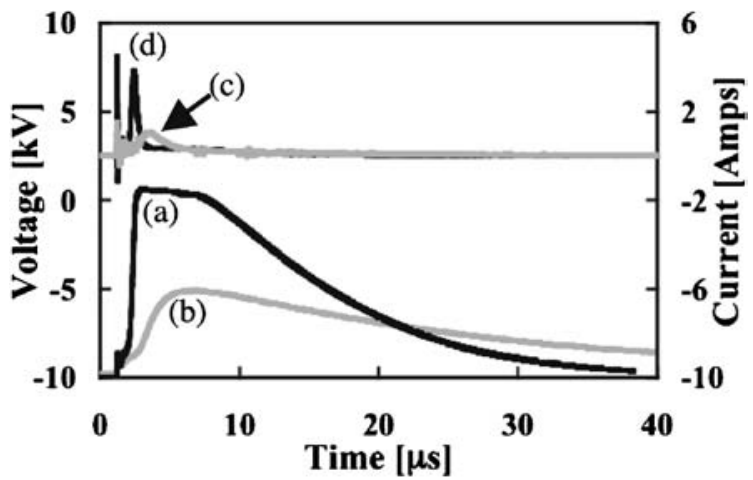

FIGURE 2 Electrical diagnostic signals: (a) voltage from previous parallel target-substrate orientation, (b) voltage from perpendicular target-substrate orientation, (c) current from perpendicular target-substrate orientation, (d) current from previous parallel target-substrate orientation

Another advantage of dc APII is that the initial current burst, Fig. 2c, of ions is accelerated at full voltage. This is in contrast to experiments utilizing the parallel targetsubstrate orientation, in which the highest ion current, Fig. 2d,

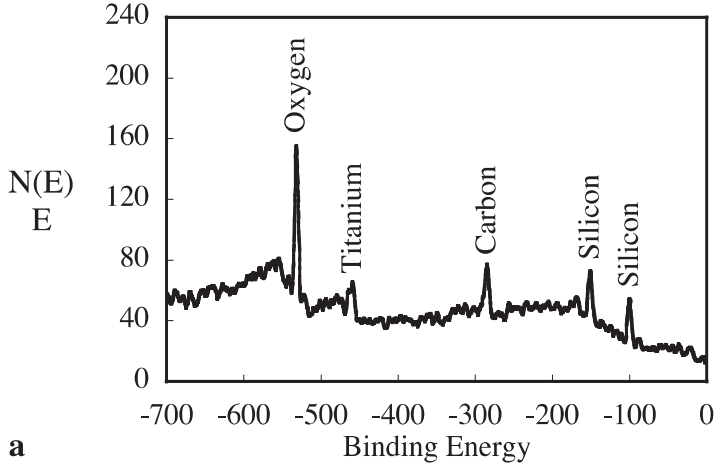

a

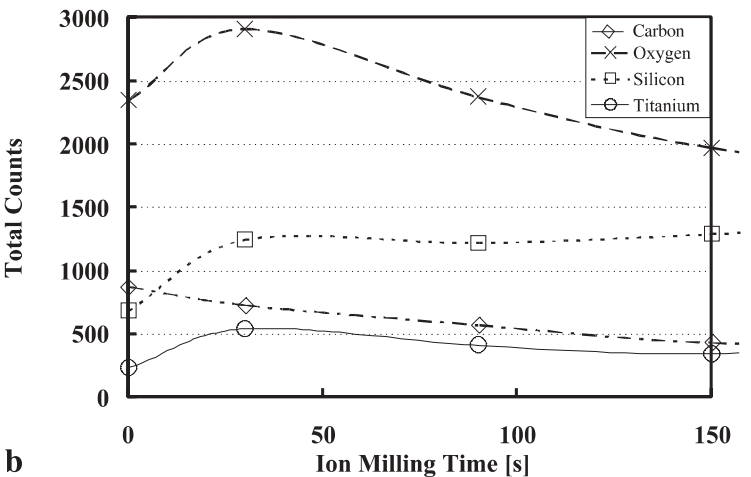

FIGURE 3 a XPS results of dc APII $(10-\mathrm{kV})$ with 5000 shots. b Total counts versus argon-ion milling time (film depth) obtained from XPS

was accelerated during the voltage short circuit at low energies.

dc ablation plasma ion implantation experiments were performed with a titanium target $(99.5 \%$ pure) and a silicon substrate. The number of pulses was typically around 5000 shots, but as many as 20000 shots were needed depending on the analysis to be performed. The samples were then analyzed by using a scanning electron microscope (SEM) and by X-ray photoelectron spectroscopy (XPS).

The SEM results show that there are fewer particulates on the surface of the Si substrate compared to the results from the parallel target-substrate orientation. This supports the idea that the particulate trajectories miss the substrate in this orientation.

The XPS results are shown in Fig. 3. Figure 3a shows a typical result showing the peaks of $\mathrm{Ti}, \mathrm{Si}, \mathrm{C}$, and $\mathrm{O}$. These results indicate that titanium exists on the surface of the silicon substrate. Carbon and oxygen are found on the surface due to contamination after the substrate was removed from the vacuum chamber. The atomic concentration of $\mathrm{Ti}$ was $20 \%, \mathrm{Si}$ was $49 \%, \mathrm{C}$ was $11 \%$, and $\mathrm{O}$ was $20 \%$.

Figure $3 \mathrm{~b}$ shows the depth profile obtained from the substrate by using an argon-ion gun to sputter away the surface. From these data it can be seen that the concentration of Ti increased as the surface was sputtered away initially, and then the counts gradually decrease. These results are significantly different from the previous parallel substratetarget orientation, in which the Ti would continuously decrease due to the film that was also being deposited on the surface.

In conclusion, we have shown that it is possible to utilize a dc power supply for ablation plasma ion implantation. 
It has also been shown that this technique deposits a minimal amount of particulates on the surface.

ACKNOWLEDGEMENTS This research was partially supported by the National Science Foundation.

\section{REFERENCES}

1 J.R. Conrad, J.L. Radtke, R.A. Dodd, J. Worzala, N.C. Tran: J. Appl. Phys. 62, 4591 (1987)

2 J.T. Sheuer, M. Shamim, J.R. Conrad: J. Appl. Phys. 67, 1241 (1990)

3 M. Ueda, L.A. Berni, R.M. Castro, A.F. Beloto, E. Abramof, J.O. Rossi, J.J. Barroso, C.M. Lepienski: Surf. Coat. Technol. 156, 71 (2002)

4 S. Qin, N. McGruer, C. Chan, K. Warner: IEEE Trans. Electron Devices 39, 2354 (1992)

5 N.W. Cheung: Mater. Chem. Phys. 46, 132 (1996)

6 B.L. Yang, N.W. Cheung, S. Denholm, J. Shao, H. Wong, P.T. Lai, Y.C. Cheng: Microelectron. Reliab. 42, 1985 (2002)
7 X. Tian, R.K.Y. Fu, P.K. Chu: J. Vac. Sci. Technol. A 20, 160 (2002)

8 B.P. Wood, I. Henins, D.J. Rej, H.A. Davis, W. Waganaar, R.E. Muenchausen, G.P. Johnson, H.K. Schmidt: Nucl. Instrum. Methods Phys. Res. B 96, 429 (1995)

9 Y.X. Leng: Thin Solid Films 398-399, 471 (2001)

10 P.K. Chu, J.Y. Chen, L.P. Wang, N. Huang: Mater. Sci. Eng. R Rep. 36, 143 (2002)

11 D.T.K. Kwok, X.C. Zeng, C. Chan, P.K. Chu: J. Appl. Phys. 87, 4094 (2000)

12 X.C. Zeng, P.K. Chu, Q.C. Chen, H.H. Tong: Thin Solid Films 390, 145 (2001)

13 X. Zeng, R.K.Y. Fu, D.T.K. Kwok, P.K. Chu: Appl. Phys. Lett. 79, 3044 (2001)

14 B. Qi: Ph.D. dissertation, University of Michigan, 2002

15 B. Qi, R.M. Gilgenbach, Y.Y. Lau, M.D. Johnston, J. Lian, L.M. Wang, G.L. Doll, A. Lazarides: Appl. Phys. Lett. 78, 3785 (2001)

16 B. Qi, Y.Y. Lau, R.M. Gilgenbach: Appl. Phys. Lett. 78, 706 (2001)

17 B. Qi, R.M. Gilgenbach, M.C. Jones, M.D. Johnston, Y.Y. Lau, L.M. Wang, J. Lian, G.L. Doll, A. Lazarides: J. Appl. Phys. 93, 8876 (2003) 